\title{
Modelagem Matemática Utilizando Processamento de Imagens Digitais em Diferentes Tratamentos de Lesões Cutâneas
}

\author{
Janine da Rosa Albarello* Scheila Cristiane Angnes Willers Marnei Zorzella \\ Mestrandas em Modelagem Matemática - UNIJUÍ - 98700-000, Ijuí, RS \\ E-mail: janine_albarello@hotmail.com \\ Jéssika Schopf Pasini \\ Graduanda Curso Medicina Veterinária(Deag) - Unijuí \\ Daniel Curvello de Mendonça Muller** \\ Departamento de Ciências Exatas e Engenharias (DCEEng), UNIJUÍ 98700-000, Ijuí, RS \\ E-mail: cmdaniel@terra.com.br
}

\section{RESUMO}

O processamento de imagens digitais (PID) pode ser utilizado em várias áreas de aplicação do conhecimento humano, resolvendo uma gama de problemas que requerem métodos capazes de melhorar a informação visual. Têm-se como exemplos, as imagens melhoradas por tratamento digital na área médica, com imagens de raios-X e ultrassonografia; na geologia $\mathrm{o}$ estudo das imagens de satélites; na restauração de figuras da arqueologia; na medicina nuclear e na melhoria de imagens transmitidas por ondas de rádio.

As feridas são frequentes na rotina hospitalar de médicos veterinários, contudo a compreensão da eficácia de tratamentos, por longo tempo foi baseada em avaliações visuais e interpretações subjetivas. Visto que a resistência bacteriana aos antibióticos vem se tornando um problema de saúde pública, tem-se buscado aumentar a gama de agentes naturais para utilização no tratamento de lesões, seja com objetivos antimicrobianos, seja reduzindo a inflamação local.

Nesse trabalho, utilizou-se a ferramenta proposta de avaliação de imagens digitais, para comparar a utilização de óleo essencial de uma planta nativa do Rio Grande do Sul, o Alecrimdo-campo (Baccharis dracunculifolia), com tratamentos já estabelecidos. O emprego desses agentes ocorreu em lesões cutâneas experimentais em ratos, promovidas em ambiente cirúrgico. Para tanto foram utilizadas 18 ratas (Wistar), divididos em três grupos, onde o grupo 1 foi tratado com o fitoterápico (Óleo essencial de alecrim), o grupo $2 \mathrm{com}$ rifamicina e o grupo 3 com solução fisiológica. Os tratamentos foram realizados nos animais de todos os grupos, diariamente, durante 21 dias. Este estudo foi aprovado pelo Comitê de Ética e Experimentação Animal da UNIJUÍ.

Através da aquisição das imagens, obteve-se imagens digitais da área das lesões, fotografadas com uma câmera digital semiprofissional (Nikon D3100), com resolução fina de 1280 x 960 pixels, sob luz fluorescente. As imagens foram obtidas sempre da mesma distância e aproximação de zoom, sendo salvas na extensão JPEG. Dessa forma foi possível comparar os animais entre si, obtendo boa qualidade de imagem. As imagens foram obtidas nos dias 1, 7, 14 e 21 após a criação cirúrgica das lesões.

Para encontrar a área das lesões foram utilizados os contornos das lesões e em seguida foi realizado o ajuste pela equação da elipse fazendo uso do método dos mínimos quadrados:

$$
a x^{2}+b x y+c y^{2}+d x+e y-1=0
$$

Finalizando esta etapa encontramos a área da elipse de cada lesão. As análises de área da ferida foram realizadas no programa MATLAB Versão 7.9.0, 2004, onde foram encontrados os contornos de cada lesão para posterior análise estatística.

\footnotetext{
* Bolsista Unijuí de Mestrado em Modelagem Matemática

** Professor Orientador
} 


\begin{tabular}{|c|c|c|c|c|c|c|c|c|c|}
\hline & \multicolumn{2}{|c|}{ DIA 1} & \multicolumn{2}{|c|}{ DIA 2} & \multicolumn{2}{|c|}{ DIA 3} & \multicolumn{2}{|c|}{ DIA 4} \\
\hline & & Cálculo elipse & Número de pixel & Cálculo elipse & Número de pixel & Cálculo elipse & Número de pixel & Cálculo elipse & Número de pixel \\
\hline \multirow{6}{*}{ G1 Oléo } & 1 & 190712.3288 & 193522.3138 & 124072.8579 & 124896.1669 & 35954.7623 & 36272.8962 & 8199.4999 & 8375.2837 \\
\hline & 2 & 297748.7261 & 302373.7402 & 119935.5761 & 121040.1031 & 42065.8901 & 42452.8239 & 9396.7717 & 9649.5444 \\
\hline & 3 & 225667.7421 & 229972.7406 & 155749.0186 & 158665.5774 & 33160.1887 & 34320.5995 & 3001.4564 & 3230.3164 \\
\hline & 4 & 160806.4401 & 164607.7401 & 115160.4136 & 117402.8812 & 23398.3194 & 23904.28 & 4945.7981 & 5451.8247 \\
\hline & 5 & 229809.0496 & 233025.1538 & 147872.3566 & 150182.9224 & 26691.2685 & 27364.1184 & 3440.9808 & 3588.909 \\
\hline & 6 & 210219.627 & 213350.0227 & 118127.5979 & 119536.677 & 23653.0057 & 24053.5811 & 4078.478 & 4326.0481 \\
\hline \multirow{6}{*}{$\begin{array}{c}\text { G2 } \\
\text { Rifamicina }\end{array}$} & 1 & 216513.319 & 219511.9592 & 118284.6431 & 120425.0179 & 19675.9291 & 20204.1158 & 3358.3982 & 3913.1971 \\
\hline & 2 & 206785.6752 & 209549.0838 & 116345.0369 & 118178.9089 & 30330.6637 & 31228.6404 & 3863.0411 & 4018.9251 \\
\hline & 3 & 178358.5959 & 181078.82 & 122510.0697 & 124712.7996 & 18804.6543 & 19238.5581 & 5811.174 & 6124.4846 \\
\hline & 4 & 210792.8936 & 213761.421 & 121938.2887 & 124696.7514 & 17247.9003 & 17812.2053 & 2093.3174 & 2175.9982 \\
\hline & 5 & 154684.3655 & 157106.2911 & 131783.0994 & 134061.5504 & 20676.9217 & 21339.8756 & 3506.3116 & 4469.7563 \\
\hline & 6 & 206896.5464 & 210320.258 & 125002.9122 & 126582.2577 & 32075.3322 & 32955.0836 & 4546.9844 & 4915.4126 \\
\hline \multirow{6}{*}{$\begin{array}{l}\text { G3 Sol. } \\
\text { fisiológica }\end{array}$} & 1 & 213034.0907 & 218234.9752 & 112589.0798 & 114212.6558 & 40873.5388 & 41479.7307 & 13161.004 & 13434.3179 \\
\hline & 2 & 209015.545 & 211073.0143 & 136801.767 & 138323.9753 & 14772.6739 & 15185.2109 & 2598.8421 & 2665.5612 \\
\hline & 3 & 219962.6625 & 223141.26 & 117601.7963 & 118653.4427 & 16710.7895 & 17173.1317 & 1000.0000 & 1000.0000 \\
\hline & 4 & 287145.9346 & 290844.0375 & 122343.5771 & 123681.7903 & 12579.6386 & 13077.4067 & 1000.0000 & 1000.0000 \\
\hline & 5 & 184394.8469 & 186466.4616 & 118155.4549 & 120739.2395 & 43420.6726 & 44392.7991 & 10482.1565 & 10840.3728 \\
\hline & 6 & 176692.4453 & 179337.8629 & 73469.2781 & 75388.8996 & 19296.627 & 19801.2321 & 1000.0000 & 1000.0000 \\
\hline
\end{tabular}

Tabela 1. Valores das áreas reais das feridas em pixel e a comparação dos resultados com a área da elipse.

\begin{tabular}{|c|c|c|c|c|c|c|}
\hline & Soma de & $\begin{array}{c}\text { Tuadrado } \\
\text { G.L. }\end{array}$ & Quadrados & Médio & Estat. F & P-valor \\
\hline Dia & 3 & 1537922.275 & 512640.7583 & 383.8848754 & 0 & $* *$ \\
\hline Rato & 5 & 5159.375599 & 1031.87512 & 0.772707291 & 0.5745 & Ns \\
\hline Fator & 2 & 4073.119737 & 2036.559869 & 1.5250534 & 0.2286 & Ns \\
\hline Dia:Fator & 6 & 5285.729453 & 880.9549088 & 0.659692504 & 0.6823 & Ns \\
\hline Rato:Fator & 10 & 20042.12116 & 2004.212116 & 1.500830174 & 0.1706 & Ns \\
\hline Resíduos & 45 & 60093.105 & 1335.402333 & & & \\
\hline
\end{tabular}

Tabela 2 - Resultados da análise de variância para área em $\mathrm{mm}^{2}$, em quatro diferentes dias de avaliação (1, 7, 14 e 21 dias pós-operatórios).

Observa-se que as variações de áreas foram mínimas, tanto entre os grupos, quanto dentro dos próprios grupos. Com os resultados obtidos, pode-se concluir que os três tratamentos utilizados, limpeza com solução fisiológica e óleo essencial de alecrim, limpeza com solução fisiológica e rifamicina e apenas limpeza com solução fisiológica não diferiram estatisticamente. Levando em conta o protocolo utilizado do óleo essencial de Alecrim-do-campo este não contribuiu com a cicatrização.

Palavras-chave: Modelagem Matemática, Fitoterápico, Imagem Digital, Feridas.

\section{Referências}

[1] Gonzales, R.C. Woods, R.E. Processamento de Imagens Digitais. Tradução de Roberto Marcondes César Junior e Luciano da Fontoura Costa - São Paulo: Editora Edgard Blucher Ltda, 2000.

[2] Knob, A. H. Aplicação do processamento de imagens digitais para análise da anisotropia da massa de grãos. Dissertação (Mestrado em Modelagem Matemática), Universidade Regional do Noroeste do Estado do Rio Grande do Sul, Ijuí, 2010.

[3] Matlab Versão 7.9.0, 2004.

[4] Silva, N.C.C. Estudo comparativo da ação antimicrobiana de extratos e óleos essenciais de plantas medicinais e sinergismo com drogas antimicrobianas. TCC, Mestrado Biologia Geral e Aplicada, Instituto de Biociências UNESP, 2010. 